https://doi.org/10.48009/1_iis_2006_175-178

\title{
ETHICAL ATTITUDES OF BUSINESS INFORMATION SYSTEMS STUDENTS: AN EMPIRICAL INVESTIGATION
}

\author{
Leila Halawi, Cookman College, halawil@ cookman.edu \\ Silva Karkoulian, Lebanese American University, skarkoul@beirut.lau.edu
}

\begin{abstract}
This paper discusses attitudes toward ethical issues in information systems. Approximately 150 subjects were drawn from two populations: full-time undergraduate business information systems students and full-time master's students. The subjects read a subset of six ethical scenarios. Hypotheses were tested for significant differences between the undergraduate students' beliefs and those of graduate students, and female and male students who responded to the same scenarios.
\end{abstract}

Keywords: Information Technology (IT), Ethics, IT and Ethics

\section{INTRODUCTION}

Information technology (IT) is introducing changes that create new ethical issues for societies to debate and resolve. Computers and communication technology are radically changing our everyday life, yet we are critically short of ethical and intellectual resources with which to understand and confront these changes [11].

Technology becomes associated with ethical issues because it is the medium through which many problematic transactions occur [3]. Increasing computer power, storage and networking capabilities including the Internet can expand the reach of individual and organizational actions and magnify their impact. The ease and anonymity with which information can be communicated, copied and manipulated in on-line environments is challenging traditional rules of right and wrong behavior [6]. To add, these changes are creating new situations where existing laws or rules of conduct may not be relevant.

Rapid change often disrupts the operable norms and values. The pace of change is so fast that sometimes it seems that the world will be completely different from one day to the next. IT won't [5]. But we should be prepared for change. Academicians warn us that it is time to reassess our institutions and values in the light of these changes. Thus the information society, a society serving all of its citizens, not only the technically sophisticated and economically privileged, is going to be asked to make hard choices. These choices are the province of ethics.

Ethics is a gray area that deals with actions that are not technically illegal, but are not quite right either [1]. Ethical issues are increasingly starting to be recognized as important aspects of information systems [2]. Viruses, cracking (sometimes called hacking), computer fraud, illegal software copying, and corporate sabotage using a computer are familiar topics in the popular press. Ethical problems are growing faster in schools, colleges and especially higher educational institutions. They affect each and every individual and transform him into a decision maker. The need to prepare students to be responsible in the workplace is a strong motivator in the emergence of computer ethics [9].

Many educators and researchers have assumed that both a problem exists and that undergraduate students hold the same ethical attitudes as MIS personnel or graduate students $[10,12]$. The present study tests the two assumptions: (a) undergraduate business information systems students preparing to enter the business world hold the same beliefs as the graduate students, and (b) female and male students hold the same ethical beliefs. In order to provide continuity within the MIS ethics research area, this study used essentially the same instrument as that used by previous researchers [8]. Since these researchers used undergraduate and graduate business information systems majors as subjects, the replication of their earlier work with different subject groups allows further comparisons.

\section{Ethical Theories and IT}

Information ethics is concerned with the ethical conflicts and issues that arise in the use of information, information technologies and information systems. One indication of the growth of this area is the appearance of courses and the attendant textbooks and readings. Information ethics and computer ethics are well documented in these publications. The intended audiences are students in graduate and undergraduate courses in management information systems, computer science, information science, business, and library and information 
science. In most discussions, major philosophical traditions in ethics are invoked.

Ethics research has been a growing area of research within the field of IS $[14,4,16,8]$. IS research practically was launched in 1986 when Mason [7] examined major ethical issues in IS. He identified these ethical issues with the acronym PAPA privacy, accuracy, property and accessibility. Numerous studies have been carried out over recent years to attend to these and further issues. Parker [13] talked about the role of ethics in information systems and offered ten steps for advancing ethical behavior in an organization. Couger [4] offered a pedagogical approach to instructing IS students to deal with ethical issues that require students to conclude how they would behave in various ethical scenarios. Solomon and O'Brien [15] examined the effects of different demographic factors on students' approaches toward piracy. Wood [17] studied the relationship between years of computer usage and ethical attitudes of IS managers and users through ethical scenarios that were presented to professionals only. The paper by McCarthy, Halawi and Aronson [8] provides a thorough review of the literature and background for the study; it is not repeated here.

\section{RESEARCH METHODOLOGY}

Our research centered upon the following research question:

Do significant ethical differences exist amongst undergraduate and graduate Business Information Systems students in Lebanon?

The research hypotheses to be tested are as follows:

$\mathrm{H}_{1}$ : Business information systems undergraduate and graduate students have the same ethical beliefs.

$\mathrm{H}_{2}$ : Female business information systems students and male business information systems students have the same ethical beliefs.

The subjects read six scenarios and were asked to classify the fourteen behaviors described in them as Unethical, Ethical, or Not an Ethics issue. The results of these classifications will be compared to each other, as well as to the results of prior studies using the same instrument. This study used the same instrument as studies by McCarthy, Halawi and Aronson [8]. The scenario technique has been shown to be useful in eliciting attitudes by personalizing the issues [5]. Their responses were anonymous.
The survey was administered to 150 college business information systems students. The sample consisted of 95 undergraduates and 55 graduate students from a medium sized university located in Beirut, Lebanon. The scenarios were personally administered.

\section{RESULTS}

The descriptive results of this study are presented in Table 1 . The sample population had $47.3 \%$ males and $52.7 \%$ females.

Table 1. Demographics

\begin{tabular}{|c|l|c|}
\hline Gender & Program & Responses \\
\hline Female & $\begin{array}{l}\text { Undergraduate Business } \\
\text { Information Systems Students }\end{array}$ & 42 \\
\hline Male & $\begin{array}{l}\text { Graduate Business } \\
\text { Information Systems Students }\end{array}$ & $\begin{array}{l}\text { Undergraduate Business } \\
\text { Information Systems Students }\end{array}$ \\
\hline & $\begin{array}{l}\text { Graduate Business } \\
\text { Information Systems Students }\end{array}$ & 26 \\
\hline
\end{tabular}

A Chi-Square test was performed to test each of the two hypotheses. The first hypothesis tested whether undergraduate and graduate business information systems students hold the same ethical beliefs. The second hypothesis tested whether female and male business information systems students hold the same ethical beliefs. A p-value was calculated for each of the six scenarios and any value less than .05 was rejected (Table 2).

Table 2. Chi-Square Values for Hypotheses (PValues)

\begin{tabular}{|l|l|l|}
\hline Scenario & H1 & H2 \\
\hline $1-1$ & 0.789 & $0.018^{*}$ \\
\hline $1-2$ & $0.000^{*}$ & 0.103 \\
\hline $1-3$ & $0.024^{*}$ & $0.035^{*}$ \\
\hline $2-1$ & 0.107 & 0.710 \\
\hline $2-2$ & 0.422 & 0.392 \\
\hline $2-3$ & $0.000^{*}$ & $0.003^{*}$ \\
\hline $3-1$ & 0.291 & $0.011^{*}$ \\
\hline $3-2$ & $0.022^{*}$ & 0.132 \\
\hline $4-1$ & 0.766 & 0.154 \\
\hline $5-1$ & $0.009^{*}$ & $0.003^{*}$ \\
\hline $5-2$ & 0.242 & 0.172 \\
\hline $5-3$ & 0.170 & 0.795 \\
\hline $6-1$ & 0.543 & 0.477 \\
\hline $6-2$ & $0.025^{*}$ & 0.492 \\
\hline
\end{tabular}

$*$ Reject $\mathrm{H}$ at $\mathrm{p}<0.05$ 


\section{CONCLUSIONS}

Examining the scenarios on which the undergraduate and graduate students disagreed shows that the two groups disagreed in their responses for six of the fourteen actions: 1-2, 1-3, 2-3, 3-2, 5-1 and 6-2. Examining the scenarios on which the female and male students disagreed shows that the two groups disagreed in five of the fourteen actions: 1-1, 1-3, 23, 3-1, and 5-1. These six scenarios should be explored carefully to assess probable explanations for these differences.

There seems to be some evidence that there is a difference in perception to ethical situations between undergraduate and graduate students as well as between females and males in certain ethical situations. The reasons for the differences might provide a good area for additional research and analysis. The prior study [8] that compared American undergraduate students with graduate students revealed the same results. It is important to note that students had not received any training relating to computer ethics within their curriculum.

Ethics research has been a growing area of research within the field of IS. The MIS personnel demonstrate a great sensitivity to ethical issues in information systems. Since this study did not determine how the students developed their ethical opinions, the area of perception regarding ethics in information systems can use some further research. It is not clear why or how students acquire a sensitive or reduced sensitivity to ethical issues in information systems.

We live in an ever-changing world in which each action has its implications. The computer revolution is growing fast and creating unethical problems at each step. These unethical problems are facing faculties and students in the educational institutions. The use of information technology places the students in a decision-making stand where being up to the level is very challenging and requires lot of autonomy and responsibility. However, through education and training, students are encouraged and required to achieve ethical competence, which empowers them. Ethical competence is, above all, one's ability to act self-confidently, autonomously and with high degree of responsibility.

So, it seems important to include formal instruction in ethics in the curriculum of business information technology programs. This notion is also supported by the IS2002 [18] curriculum development. This undertaking should not be limited to the academic world. Businesses and other associations may possibly care for developing workshops for new IS recruits that contemplate IS-related states instead of applying merely common business situations.

\section{REFERENCES}

1. Anderson, J. (1997). What cognitive science tells us about ethics and the teaching of ethics, Journal of Business Ethics 16, 279-291.

2. Anonymous. (2005). Responsible Management of Information Systems. Information Technology Newsletter. Hershey: Jan- Jun 16(1), 24-26.

3. Andrews, P. T. (1997). Ethical implications of technological advances on business communication. The Journal of Business Communication, 34(2), 160-170.

4. Couger, D. J. (1989). Preparing IS students to deal with ethical issues. MIS Quarterly, 13(2), 211-218.

5. Gates, B. (1995). The Road Ahead. Viking Penguin Group.

6. Laudon, K. C. (1995). Ethical concepts and information technology. Communication of the ACM, 38(12), 33-39.

7. Mason, R. O. (1986). Four ethical issues of the information age. MIS Quarterly, 10(1), 4-12.

8. McCarthy, R., Halawi, L. \& Aronson, J (2005). Information technology ethics: a research framework. Issues in Information Systems: The 21st Century Challenges to Information Technology, VI(2), 64-69.

9. Moore, J. H. (1985). What is computer ethics. Metaphilosophy, 16(4), 266-275.

10. Morris, A., Jones, G. \& Rubinsztein, J. (1993). Entry-level information systems personnel: A comparative study of ethical attitudes. Proceedings of the 1993 ACM SIGCPR Conference.[online] St Louis MoUSA, 8-17. Available www.acm.org/pubs/articles/ proceedings/cpr/158011/p8-morris/p8-morris.pdf

11. Osif. B.A. (2005). Computer and Internet ethics. Library Administration \& Management, 19(3), 149-154.

12. Paradice, D. B., \& Dejoie, R. M. (1991). The ethical decision-making processes of information systems workers. Journal of Business Ethics, 10, 1-21.

13. Parker, D.B. (1980). Ethical Conflicts in Computer Science and Technology, AFIPS Press.

14. Shim, J. \& Taylor, S. (1988). A comparative study of unauthorized software copying: information systems faculty members vs. practicing managers' perceptions. OR/OM Today, 15(5), 189-198. 
15. Solomon, W.L. \& O'Brien, J. A. (1990). The effects of demographic factors on attitudes toward software piracy, The Journal of Computer Information Systems, Spring, 40-46.

16. Thong, J. \& Yap, C. (1998). Testing an ethical decision-making theory: the case of softlifting.
Journal of Management Information Systems, 15(1), 213-237.

17. Wood, W. A. (1993). Computer ethics and years of computer use. Journal of Computer Information Systems, Summer, 23-27. www.is2002.org, retrieved December 24, 2005. 